Proc. Indian Acad. Sci. (Chem. Sci.), Vol. 89, Number 2, April 1980, pp. 95-99.

(C) Printed in India.

\title{
Spectrophotometric determination of iron(III) with $\mathbf{N}$-hydroxy- $\mathbf{N}$ - phenyl- $\mathrm{N}^{\prime}$-(2-methyl)phenylbenzamidine hydrochloride in presence of thiocyanate and azide
}

\author{
HEMLATA MOHABEY, PRAMOD KUMAR SHARMA and \\ RAJENDRA K MISHRA \\ Department of Chemistry, Ravishankar University, Raipur 492010 , India
}

MS received 16 November 1979; revised 24 January 1980

\begin{abstract}
N-hydroxy-N-phenyl-N'-(2-methyl)phenylbenzamidine hydrochloride reacts with iron(III) in the presence of thiocyanate and azide forming coloured mixed complexes which are quantitatively extractable into benzene. The extractability can be explained on the basis of formation of $1: 1: 2$ (metal : HPMPBH : $\mathrm{SCN} / \bar{N}_{2}$ ) tornary species which are hydrophobic in nature. The methods based on these sensitive colour reactions are fairly selective.
\end{abstract}

Keywords. Solvent extraction ; spectrophotometric determination ; iron(III) ; thiocyanate ; azide.

\section{Introduction}

The parent thiocyanate method (Sandell 1959), which is frequently used for spectrophotometric determination of iron(III), suffers from various experimental limitations such as the amount of thiozyanate, the time of standing, nonlinearity of Beer's law, reproducibility, etc. Even the modified method (Wood and Mellon 1941) lacks selectivity (Kolthoff and Sandell 1952). Yamamoto and Ohashi's (1977) method based on the formation of mixed ligand complexes of iron(III) with $\mathrm{N}$-hydroxy ethylenediamine $N, N^{\prime}, N^{\prime \prime}$-triacetate and thiocyanate is fairly selective but less sensitive. $\mathrm{N}$-hydroxy-N, $\mathrm{N}^{\prime}$-diaryl benzamidines, a new type of organo analytical reagents (Satyanarayana and Mishra 1974, 1976; Deb and Mishra 1978, 1979; Patel and Mishra 1978) have been found to react with iron(III) producing $p^{\text {H. }}$ dependent blue and red purple colour in alcohol which are useful for colorimetric determination of iron(III) but the method suffers from interferences of several common ions (Satyanarayana and Mishra 1976). A new method has been developed using a newly synthesised hydroxyamidine, $\mathrm{N}$-hydroxy-N-phenyl- $\mathrm{N}^{\prime}$-(2methyl)phenylbenzamidine hydrochloride with thiocyanate and azide for solvent extraction and spectrophotometric determination of iron(III). The formation of thiocyanate/azido mixed complexes of iron(III) with HPMPBH not only increases 
the sensitivity but also the selectivity. The method developed on the basis of colour reaction of HPMPBH with iron(III) in the presence of thiocyanate is highly sensitive. The selectivity of the method is comparable with other commonly used colorimetric methods for iron(III) (Snell et al 1967). Fe(III) : HPMPBH : $\overline{\mathbf{N}}_{\mathbf{3}}$ ternary system also bases a rapid, simple and selective method which affords the separation of iron(III) from nickel, cobalt, zinc, cadmium, etc., in a singlo extraction.

\section{Experimental}

\subsection{Apparatus}

The spectra were recorded with a Carl-Zeiss UV-VIS specord spectrophotometer. An ECIL spectrophotometer model GS-865 equipped with $1 \mathrm{~cm}$ matched quartz and silica cells, was employed for absorbance measurements. The $p^{\mathrm{H}}$ values were determined with a systronic $p^{\mathrm{B}}$ meter type-322.

\subsection{Standard iron(III) solution}

Stock solution of iron(III) was prepared by dissolving $0.56 \mathrm{~g}$ of pure iron wire ( $\mathrm{E}$ Merck) in $50 \mathrm{ml} \mathrm{1:3}$ nitric acid. It was boiled to expel oxides of nitrogen and diluted to 1 litre. It was standardised gravimetrically with 8-hydroxyquinoline (Vogel 1964).

Aqueous solution of potassium thiocyanate and sodium azide $(2 \% \mathrm{w} / \mathrm{v})$ were also prepared. All the chemicals used were of AnalaR grade.

2.3. Preparation of $N$-hydroxy-N-phenyl-N'-(2-methyl)phenylbenzamidine hydrochloride

The reagent HPMPBH was prepared by condensation of equimolar quantities of N-(2-methyl)phenylbenzamidoyl chloride and N-phenylhydroxylamine in ether (Deb and Mishra, 1976). The resulting hydrochloride was crystallised from absolute alcohol, m.p. $197^{\circ} \mathrm{C}$; Yield $80 \%$ (Found C, 70; H, 5.68; N, 8.37; Calculated for $\mathrm{C}_{20} \mathrm{H}_{19} \mathrm{~N}_{2} \mathrm{OCl}$ : C, $70.9 ; \mathrm{H}, 5.9 ; \mathrm{N}, 8.2 \%$ ).

A $0.1 \%$ solution of HPMPBH in benzene were used for extraction purposes.

\subsection{Procedure}

An aliquot of iron(III) solution containing 50 to $100 \mu \mathrm{g}$ of the metal was placed in a $125 \mathrm{ml}$ soparatory funnel. To this $5 \mathrm{ml}$ of $2 \%$ potassium thiocyanato/azide solution was added. The acidity was adjusted to the required value and diluted to $25 \mathrm{ml}$. The solution was equilibrated for $2 \mathrm{~min}$ with $25 \mathrm{ml}$ of $0.1 \%$ benzene solution of HPMPBH. The benzene extract was then dried over anhydrous sodium sulphate. The absorbance of the coloured species was measured at the wavelength of maximum absorption against reagent blank. 


\section{Results and discussion}

\subsection{Absorption spectra}

The absorption spectra of mixed thiocyanate and azido complexes of iron(III) with HPMPBH and reagent in benzene are shown in figure 1. HPMPBH reacted with iron(III) in the presence of thiocyanate forming an orange-red benzene extractable ternary complex which absorbed strongly at $460-470 \mathrm{~nm}$. The ternary ironHPMPBH-azide complex was violet in colour and absorbed strongly at $520 \mathrm{~nm}$. The reagent showed negligible absorbance in the region $450-700 \mathrm{~nm}$, hence was replaced by benzene.

\subsection{Effect of variables}

The acidity of the aqueous phase was adjusted with $2 \mathrm{M}$ hydrochloric acid and dilute ammonia. The optimum acidity range for iron-thiocyanate mixed ligand complexes of HPMPBH was found to be $0.20-0.70 \mathrm{M}$ hydrochloric acid in which iron(III) was quantitatively extracted. Below $0.2 \mathrm{M}$ and beyond $0.70 \mathrm{M} \mathrm{HCl}$ concentration low absorbance values were obtained. The azide ternary complex was completely extractable at $2 \cdot 0-5 \cdot 0 \mathrm{p}^{\mathrm{n}}$.

In thiocyanate system a 30 and 130-fold molar excess of HPMPBH and thiocyanate, respectively, were adequate for complete extraction. The azide ternary

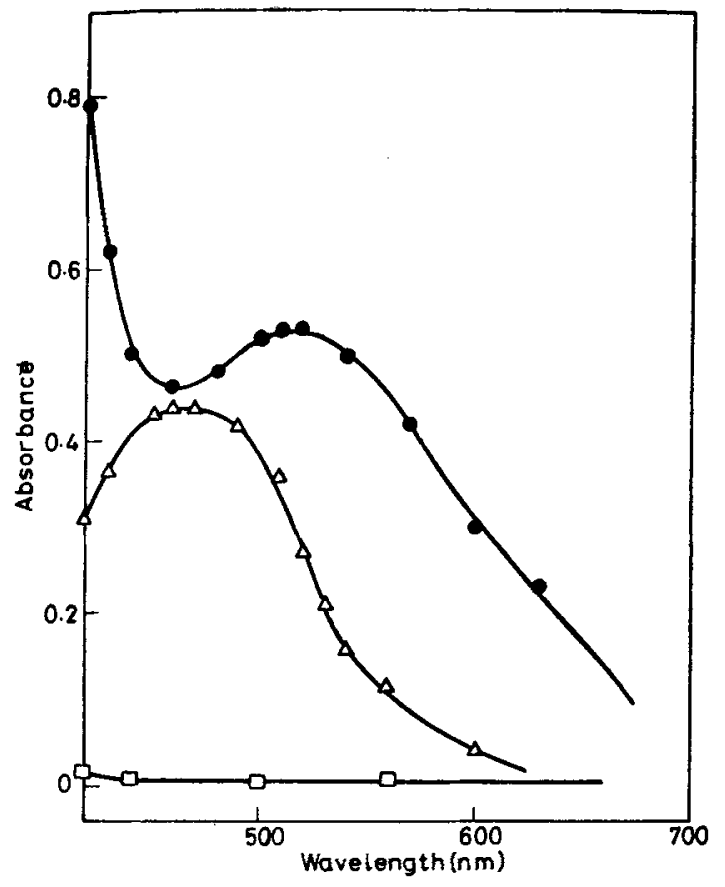

Figure 1. Absorption spectra. $\longrightarrow \longrightarrow-5.6 \mathrm{ppm}$ iron (III) $+\mathrm{N}$-hydroxy-Nphenyl- $\mathrm{N}^{\prime}$-(2-methyl)phenylbenzamidine hydrochloride + azide. $-\Delta-\Delta-\Delta-2 \mathrm{ppm}$ iron(III) $+\mathrm{N}$-hydroxy-N-phenyl-N'-(2-methyl)phenylbenzamidine hydrochloride + thiocyanate. $\quad-\square-\square-\square-0.1 \% \mathrm{~W} / \mathrm{V}$ N-hydroxy-N-phenyl-N'-(2-methyl) phenylbenzamidine hydrochloride in benzene. 
system required a 25 and 100-fold molar excess of HPMPBH and azide respectively. Addition of excess of reagents caused no adverse effect on the absorbance values of the mixed complexes. Order of addition of reagents was not critical.

A time of 2 min was sufficient for complete extraction. Both the systems were stable for at least $30 \mathrm{hr}$ at $27 \pm 2^{\circ} \mathrm{C}$. Variation in temperature from 20 to $40^{\circ} \mathrm{C}$ did not influence the absorbance values of these coloured systems. The volume of aqueous phase could be varied between $10 \mathrm{ml}$ to $60 \mathrm{ml}$ without affecting the absorbance values of the extracted mixed species.

Electrolytes such as sodium chloride, ammonium chloride, ammonium nitrate, etc., did not influence the absorbance of the coloured system and the percentage extraction of iron(III).

\subsection{Molar absorptivity, sensitivity, Beer's law, optimum concentration range and precision}

The Sandell sensitivities of thiocyanate and azido mixed complexes of iron(III) with HPMPBH were $0.0045 \mu \mathrm{g} / \mathrm{cm}^{2}$ and $0.010 \mu \mathrm{g} / \mathrm{cm}^{2}$ of iron(III). The iron(III) concentration ranges which follow Beer's law were 0.4-4.8 ppm of iron(III) for thiocyanate system and $0.6-12.0 \mathrm{ppm}$ for azide system. Ringbom plot (Ringbom 1938) suggested the effective and optimum metal concentration range $0 \cdot 8-4 \cdot 0$ and $2 \cdot 0-11 \cdot 0 \mathrm{ppm}$ for thiocyanate system and azide systems respectively. The relative standard deviation of the methods based on thiocyanate and azide colour reactions was \pm 0.55 and $\pm 0.60 \%$ respectively for 10 independent measurements.

\subsection{Nature of complexes}

The stoichiometry of thiocyanate and azide mixed ligand complexes were determined by the curve fitting method (Sillen 1956). The results indicated the formation of $1: 1: 2$ (metal : HPMPBH : thiocyanate/azide) ternary complexes.

\subsection{Effect of diverse ions}

To study the effect of diverse ions, a fixed amount of iron(III) was mixed with known quantity of foreign ion and the extraction of iron was carried out according to the recommended procedure. Reasonable amounts of chloride, bromide, nitrate, sulphate, tartrate, urea, thiourea, selenate, tellurate, alkali and alkaline earth metals and lanthanoids did not interfere with the determination of iron in both systems. The tolerance limits of other ions (in ppm) which caused an error less than $\pm 2 \%$ are shown in parenthesis.

\subsection{Thiocyanate system}

(0.3 $\mathrm{M} \mathrm{HCl}, 2 \mathrm{ppm}$ iron) Fluoride $(1000)$; phosphate or arsenate $(1,600), \mathrm{Ni}^{2+}$, $\mathrm{Co}{ }^{2+}(600), \mathrm{Zn}^{2+}, \mathrm{Cd}^{2+}(1,500), \mathrm{Al}^{3+}(800), \mathrm{Cr}^{3+}(600), \mathrm{Fe}^{2+}(800), \mathrm{Mn}^{2+}(800)$, $\mathrm{Se}^{4+}(400), \mathrm{Th}^{4+}(100), \mathrm{Zr}^{4+}(600), \mathrm{V}^{5+}(50), \mathrm{Mo}^{6+}(10), \mathrm{W}^{6+}(50), \mathrm{U}^{6+}(600) . \mathrm{Mn}^{2+}$ inhibits colour development. The interference was eliminated by ammonium persulphate. Copper ${ }^{2+}$ reacted with reagent in thiocyanate media giving brown coloured complex which was coextracted with iron and interfered seriously, but in the pre- 
sence of thiourea and by controlling the amount of reagents (a requisite amount of thiocyanate and HPMPBH) $200 \mathrm{ppm}$ of copper could be tolerated.

\subsection{Azide system}

(p⿱一土 $2 \cdot 5 \pm 0 \cdot 2 ; 4 \mathrm{ppm}$ iron(III)) Phosphate (400), arsenate (600), $\mathrm{Ni}^{2+}, \mathrm{Co}^{2+}(600)$, $\mathrm{Cu}^{2+}(100), \mathrm{Al}^{3+}(600), \mathrm{Cr}^{3+}(500), \mathrm{Fe}^{2+}(600), \mathrm{Mn}^{2+}(200), \mathrm{Th}^{4+}(600), \mathrm{Ti}^{4+}(100)$, $\mathrm{Zr}^{4+}(800), \mathrm{Mo}^{6+}(50), \mathrm{W}^{6+}(200), \mathrm{U}^{6+}(400)$.

\section{Conclusion}

The proposed methods based on the extraction of iron(III) as thiocyanato-azido ternary complexes with $\mathrm{N}$-hydroxy- $\mathrm{N}$-phenyl- $\mathrm{N}^{\prime}-(2-$ methyl) phenylbenzamidine hydrochloride are simple, rapid, sensitive and are suitable for the determination of microgram quantities of iron(III). The methods are fairly selective and several foreign ions do not interfere.

\section{Acknowledgements}

The authors are thankful to Head of the Department for providing research facilities. The award of a teacher Fellowship to HM from UGC and a Junior Research Fellowship to PKS from CSIR, New Delhi, are gratefully acknowledged.

\section{References}

Deb K K and Mishra R K 1976 J. Indian Chem. Soc. 53178

Dob K K and Mishra R K 1978 J. Indian Chem. Soc. 55462

Deb K K and Mishra R K 1978 Talanta 25698

Kolthoff I M and Sandell E B 1952 Text book of quantitative inorganic analysis (New York: The Macmillan Co.) p 636

Patel K S and Mishra R K 1978 J. Indian Chem. Soc. 55462

Ringbom A 1938 Z. Anal. Chem. 115332

Sandell E B 1959 Colorimetric determination of traces of metals (New York: Interscience Publishers)

Satyanarayana K and Mishra R K 1974 Anal. Chem. 461609

Satyanarayana K and Mishra R K 1976 J. Indian Chem. Soc. 53 63, 469, 928

Sillen L G 1956 Acta Chem. Scand. 10185

Snell F D, Snell C T and Snell C A 1967 Colorimetric methods of analysis (New York : D van Nostrand Co. Inc.)

Vogel A I 1964 A text book of quantitative inorganic analysis (London: Longmans Green and Co. Ltd.) p 524

Wood J T and Mellon M G 1941 Ind. Eng. Chem. Anal. Ed. 13551

Yamamoto K and Ohashi K 1977 Anal. Chem. Acta 88141 